\title{
Selection of contingent vs. noncontingent schedules of visual stimulation by infants
}

\author{
JENNIFER WHEELER MAKIN \\ George Peabody College, Vanderbilt University, Nashville, Tennessee 37203
}

and

\author{
RICHARD DENI \\ Rider College, Lawrenceville, New Jersey 08648
}

\begin{abstract}
Two experiments are reported showing that infants 11-20 months of age preferred noncontingent variable-time exposure to color slide stimuli over either contingent variable-interval or continuous reinforcement. Selection of one schedule over the other by subjects required their walking from side to side in a small test room. In both experiments, infants showed a significant position preference for the side of the test room in which the noncontingent schedule was operating. Differences in operant leverpressing are also reported. Stimulation preferences are discussed in terms of interactions between exploratory locomotion and attention to noncontingent visual stimuli.
\end{abstract}

Stimulation of infants with response-contingent changes in the environment has been described as a prerequisite for normal behavioral development and as normally present in infant-caregiver interaction and dialogue (Watson \& Ramey, 1972). Interruptions in response-contingent stimulation, as with maternal deprivation, have been implicated as causal factors in the early manifestation of failure-to-thrive syndrome in infants not developing normally (Ramey, Starr, Pallas, Whitten, \& Reed, 1975) and in the development of difficultness in high-risk infants (Field, 1979).

Finkelstein and Ramey (1977) have reported that infants provided with response-contingent visual stimulation learned new tasks more efficiently than did those provided with noncontingent stimulation. Finkelstein and Ramey also reported that in certain situations, infants receiving noncontingent stimulation attended more than did those receiving contingent stimulation (differences not statistically significant). The latter finding suggests that visual (or motor) exploration may, under certain conditions, be facilitated by noncontingent visual stimulation, even when operant response measures indicate that contingent consequences are reinforcing behavior.

This proposition was tested in two experiments in which the operant leverpressing of older infants was measured during concurrent contingent and noncontingent schedules selected by differential locomotion to specific "response stations" in the test room. A measure

Address reprints to Richard Deni, Psychology Department, Rider College, Lawrenceville, New Jersey 08648. We thank the families who volunteered and Robyn Martin and Meryl Silvers for their assistance in recruiting subjects. of schedule preference was obtained by recording the amount of time spent in proximity to each corresponding station. This test procedure provided data on preference for noncontingent visual stimulation when a visual and motor exploration capability was present and separate from the manual operant behavior.

\section{GENERAL METHOD}

Subjects

Male and female infants 11-20 months of age were used as subjects. The ability to walk independently was the only subjectselection criterion.

\section{Apparatus}

A small laboratory room was used for testing. A $60 \times 60 \mathrm{~cm}$ rear-projection screen was located on the right and left sides of one wall of the room. The center points of the screens were $120 \mathrm{~cm}$ apart. A standard operant response lever was mounted to the side of each screen $40 \mathrm{~cm}$ from floor level. A $60 \times 60 \mathrm{~cm}$ weight-sensitive switch pad was placed on the floor directly in front of each screen. These pads recorded the occurrence of an infant standing in front of a given screen. The response levers would not function unless the infant had first stepped on the corresponding switch pad. Two Carousel projectors were loaded with identical color slides of several "Sesame Street" characters and were set up to project from behind each screen. The experimental contingencies were controlled by laboratory microcomputer (Radio Shack TRS-80, LVB Corporation interface).

\section{Procedure}

Each test session lasted $12 \mathrm{~min}$. During the session, two schedules of stimulation were in effect. One side of the twoscreen configuration (side determined at random) was set to display $5 \mathrm{sec}$ of slide stimulation on a contingent schedule. The remaining side of the apparatus was set to display slides on a noncontingent schedule. The response lever associated with the contingent schedule was functional, whereas the other lever was not, although presses on both levers were recorded. Infants activated each schedule separately by walking toward and 
standing in front of either projection screen (activating the corresponding switch pad on the floor). Prior to the start of each session, the parent was asked to sit near the apparatus but not to interfere with its operation. No other restrictions were placed on parent-child interaction. Before the session, each infant was shown how the levers worked and was familiarized with the apparatus.

Two dependent measures were recorded, including duration of time spent in front of each screen and total number of leverpresses on each schedule. Some subjects were tested a second time on a different day because of initial fussiness. The duration of time spent located in front of each screen was used as a measure of schedule and response-station preference.

\section{EXPERIMENT 1}

This experiment involved the self-selection of contingent variable-interval (VI) vs. noncontingent variabletime (VT) schedules of visual stimulation.

\section{Method}

Fifteen infants (seven male, eight female) 11-20 months of age were used as subjects. Two schedules were available throughout the single test session, including (1) leverpress-contingent VI $1.25 \mathrm{sec}$ and (2) the noncontingent VT schedule described above. VI intervals ranged from .5 to $2.0 \mathrm{sec}$, with each interval selected at random.

\section{Results and Discussion}

The means, standard deviations, and analyses of variance results for each dependent measure are presented in Table 1. Subjects spent significantly more time located in front of the screen on which the noncontingent VT schedule of slide presentation was occurring. The average of total leverpresses was consistently higher in the noncontingent schedule condition, but this difference was not statistically significant. These subjects did, however, prefer to receive noncontingent visual displays over the opportunity to perform on a contingent VI schedule. With younger infants, findings by Finkelstein and Ramey (1977) might suggest that the opposite will occur and that a preference will be demonstrated for contingent stimulation because the preference itself can be viewed as a prerequisite for developing control over the environment. A likely factor contributing to the pattern of present results was the response

Table 1

Means, Standard Deviations, and Analyses of Variance Results for Schedule Preference and Total Leverpresses

\begin{tabular}{lccc}
\hline Schedule Condition & Mean & SD & F Ratio \\
\hline \multicolumn{4}{c}{ Preference for Reinforcement Schedule: Time (in Seconds) } \\
Positioned in Front of Each Screen \\
Contingent VI & 74.8 & 70.7 & \\
Noncontingent VT & 240.6 & 164.8 & $11.13^{*}$ \\
\multicolumn{4}{c}{ Total Number of Leverpresses per Session } \\
Contingent VI & 20.3 & 22.1 & \\
Noncontingent VT & 32.2 & 32.1 & 1.29 \\
\hline
\end{tabular}

*One-way within-subjects analysis of variance $(d f=1,14, p<.05)$. requirement of the VI schedule. Various time delays were involved in the completion of each VI. Several studies have indicated that a delay of only $3 \mathrm{sec}$ obscures a contingency for young infants (Millar \& Schaffer, 1972; Millar \& Watson, 1979; Ramey \& Ourth, 1971). This effect was explained in terms of a memory deficit or interference effect. With regard to the present data, all infants performed on the VI schedule to a degree, but they did not develop a tendency to continue that performance. Rather, they preferred the noncontingent display, on average.

\section{EXPERIMENT 2}

This experiment was a replication of the first procedure with a continuous reinforcement (CRF) schedule substituted for the contingent VI schedule. CRF was selected to provide a comparison schedule that did not involve any reinforcement delay. It was predicted that the contingent schedule would be preferred under these circumstances.

\section{Method}

A second sample of 11 infants (5 males, 6 females) 1320 months of age was used. Two schedules were available throughout the single test session, including (1) leverpresscontingent CRF and (2) the noncontingent VT schedule described previously. During CRF portions, slide onset was immediately contingent upon lever switch closure. The dependent measures from Experiment 1 were used again here.

\section{Results and Discussion}

The means, standard deviations, and analyses of variance results for each dependent measure are presented in Table 2. As in Experiment 1, subjects spent significantly more time located in front of the screen on which the noncontingent VT schedule of slide presentation was occurring. Differences in total leverpresses also paralleled the Experiment 1 findings; however, this time, there was a significant tendency to press the noncontingent lever over the contingent lever. Distribution of leverpressing was, of course, determined by selection or preference for a given response station. These results were not expected. With the delay-of-

Table 2

Means, Standard Deviations, and Analyses of Variance Results for Schedule Preference and Total Leverpresses

\begin{tabular}{lccc}
\hline Schedule Condition & Mean & SD & F Ratio \\
\hline \multicolumn{4}{c}{ Preference for Reinforcement Schedule: Time (in Seconds) } \\
Positioned in Front of Each Screen \\
Contingent CRF & 130.8 & 89.7 & \\
Noncontingent VT & 250.1 & 94.2 & $6.69 *$ \\
Total Number of Leverpresses per Session \\
Contingent CRF & 12.6 & 10.3 & \\
Noncontingent VT & 33.5 & 19.9 & $12.22^{*}$ \\
\hline
\end{tabular}

*One-way within-subjects analysis of variance $(d f=1,10, p<.05)$. 
reinforcement feature removed from the contingent stimulation, it was predicted that the CRF response station would be preferred.

\section{GENERAL DISCUSSION}

The infants tested did not show reliable preferences for the more contingent of two "response stations" at which they could press a lever to turn on color slides of "Sesame Street" characters. Rather, when amount of time spent standing in front of each response-station projection screen was used as a measure of preference, the infants significantly preferred the noncontingent station, where slides were projected automatically. Also, a contingent reinforcement schedule that did not involve a responseconsequence delay (CRF) did not reverse the response-station preference compared with a contingent schedule with delays (VI). It appears that certain features of the noncontingent response station were attractive to the subjects. The present findings relate to those reported by Millar $(1974,1975)$ involving the measurement of attentional behavior during operant acquisition of a manipulative response by 6- and 9-month-old infants. Millar paired a cue with noncontingent visual stimulation and found later that reliably more visual fixation was directed at the noncontingent display compared with the contingent display. Millar referred to the cue as having properties of "holding" visual attention, and in that case, it held visual attention to the noncontingent feedback source. The present data can be further interpreted in similar terms, in that the response stations were discriminable and holding cues were present. It is likely that the phenomenon reported by Millar was operating in the present situation to facilitate stimulation preference. Millar explained the preference he obtained as an effect of the lack of predictability and informational uncertainty associated with noncontingent stimulation. This suggests that when the origin of visual stimuli cannot be predicted or explained by infants, they will attend to them more. The infants in the present study were allowed to explore the test environment and move back and forth between two response stations at which operant levers were available. It may be that infants are especially attracted to noncontingent stimulation under these circumstances (with abundant holding cues present) and tend to show less attraction or even avoidance under circumstances in which their gross movement is restricted (such as crib or chair testing).

\section{REFERENCES}

Field, T. Games parents play with normal and high-risk infants. Child Psychiatry and Human Development, 1979, 10, $41-48$.

Finkelstein, N. W., \& RAmey, C. T. Learning to control the environment in infancy. Child Development, 1977, 48, 806-819.

Millar, W. S. The role of visual-holding cues and the simultanizing strategy in infant operant learning. British Journal of Psychology, 1974, 65, 505-518.

Millar, W. S. Visual attention to contingent and non-contingent stimulation in six- and nine-month-old infants. Psychological Research, 1975, 37, 309-319.

Millar, W. S., \& Schaffer, H. R. The influence of spatially displaced feedback on infant operant conditioning. Journal of Experimental Child Psychology, 1972, 14, 442-453.

Millar, W. S., \& Watson, J. S. The effect of delayed feedback on infant learning reexamined. Child Development, 1979, 50, 747-751.

RAMEY, C. T., \& OURTH, L. L. Delayed reinforcement and vocalization rates of infants. Child Development, 1971, 42, 291-297.

Ramey, C. T., Stark, R. H., Pallas, J., Whitten, C. F., \& REED, V. Nutrition, response-contingent stimulation, and the maternal deprivation syndrome: Results of an early intervention program. Merrill-Palmer Quarterly, 1975, 21, 45-53.

Watson, J. S., \& RAmey, C. T. Effects of response-contingent stimulation. Merrill-Palmer Quarterly, 1972, 18, 219-227.

(Received for publication November 19, 1981.) 